\title{
1 Effects of Ramadan on food intake, glucose homeostasis, lipid profiles and
}

\section{2 body composition}

3

4 5

6

7

8

9

10

11

1. Research Center for Environmental Determinacies of Health, School of Public Health, Kermanshah University of Medical Sciences, Kermanshah, Iran

E.mail: m.nachvak@kums.ac.ir

E.mail: yahya.pasdar@ kums.ac.ir

E.mail: $\underline{\text { m.darbandi@ kums.ac.ir }}$

E.mail: Ssondos_2006@yahoo.com

2. Department of Nutrition, School of Public Health ,Kermanshah University of Medical Sciences, Kermanshah, Iran

E.mail: parisaniazi44@yahoo.com

E.mail: r_mostafai@yahoo.com

3. Institute of Biological and Environmental Science, University of Aberdeen, Aberdeen, Scotland, UK and Institute of Genetics and Developmental Biology, Chinese Academy of Sciences, Beijing, China.

*Correspondence: John R Speakman and Mostafa Nachvak

Tel : +44 1224272879

Email: j.speakman@abdn.ac.uk m.nachvak@kums.ac.ir

Fax: +44 1224272396 
27 Abbreviations

28 Body mass index

BMI

29 waist-to-hip ratio

WHR

30 mass of body fat

$\mathrm{MBF}$

31 Total body water

TBW

32 percent of body fat

PBF

33 lean body mass

LBM

34 soft lean Mass

SLM

35 Low density lipoprotein

LDL

$36 \quad$ High density lipoprotein

HDL

37 Triglyceride

TG

38 Total cholesterol

TC

39 Fasting blood glucose

FBS

40

Homeostatic model assessment of insulin resistance

HOMA-IR

41 Food frequency questionnaire

FFQ

42

43

44

45

46

47

48

49

50

51

52 
ABSTRACT

54 Background: Changes in food consumption patterns during Ramadan may cause metabolic changes, but these have not been well studied.

Objective: We aimed to determine food intake, glucose homeostasis, lipid profiles and body composition before, during and after Ramadan fasting.

Methods: 160 healthy men were enrolled and investigated at three times (before, at the end of, and one month after Ramadan). Body composition was estimated by bio-impedance. Fasting blood samples were obtained for measuring fasting blood sugar (FBS), lipid profiles and insulin level. Insulin resistance was identified by the homeostatic model assessment (HOMA) of peripheral insulin resistance (IR). Food intake was measured using a validated food frequency questionnaire before and during Ramadan. Statistical analysis was performed by SPSS 16 and $P<0.05$ considered the level of significance.

Results: Anthropometric parameters such as body weight, body mass index, and body fat percentage (BFP) as well as FBS and circulating triglycerides were all decreased significantly at the end of Ramadan compared to the same indices measured prior to Ramadan (all $P<0.001)$. In contrast, at the end of Ramadan, HOMA-IR was significantly elevated $(P<0.001)$. One month after Ramadan, these traits had all started to return to their preRamadan levels, but were still disrupted. Food intake of all food groups except carbohydrates were decreased during Ramadan.

Conclusion: Ramadan fasting may lead to both positive and negative health effects such as a decrease in FBS, weight , BFP, increase in LDL and insulin resistance in healthy adults. However, these effects were all transitory.

75

Key words Ramadan, Blood glucose, Body composition, Insulin resistance, Calorie restriction. 


\section{INTRODUCTION}

At least, one billion of the total global population of Muslims (approximately 1.5 billion) (1) abstain from eating or drinking from sunrise to sunset during the holy month of Ramadan (2). Since the Islamic calendar is lunar, the beginning of the Islamic year advances 11 days each year, compared with the Gregorian calendar. Therefore, Ramadan starts at different times of year over a 33-year cycle (3). The fasting period per day may vary depending on the geographical location of the country and the season, and can be as long as 18 hours/day in the summer (4) in some locations.

Adherence to the Ramadan fast causes radical changes in lifestyle, eating patterns, and the quality of ingested nutrients $(4,5)$. The effects of Ramadan on energy balance and weight regulation have been well studied: but with some conflicting outcomes. Hence some studies indicate weight loss (including both fat and fat-free mass)(6-13), but in other studies body weight and body composition remain unchanged (14-20) and may even increase (1). Effects on food intake generally are not significant $(8,11,12,18,20)$ but that may reflect the poor quality the tools to resolve food intake differences (21). Resting metabolic rate and physical activity levels may decline $(10,22)$ but these seem to be offset by a reduction in sleeping time, and hence there is no impact on total daily energy expenditure as measured by doubly-labeled water (22). All studies agree, however, that there are profound impacts on the circadian patterns of various hormones including leptin, adiponectin, prolactin, insulin and cortisol. These changes may have downstream impacts on insulin resistance $(5,23)$. Moreover there are documented impacts of Ramadan on fasting glucose and serum lipid profiles, but the effects are also inconsistent across studies $(24,25,26)$. In the present study we investigated changes in anthropometric indices, fasting blood sugar, serum lipid profiles, serum insulin and insulin resistance at three times (before, at the end of and one month after Ramadan) and food intake before and during Ramadan in a group of 160 males. 


\section{METHODS}

This observational study was performed in Kermanshah, Iran in the summer of 2014. The study protocol was approved by the Ethics Committee of the Kermanshah University of Medical Sciences (approval no: 91058) and was registered as a clinical trial with the Iranian clinical trials registry (registration number IRCT201702269856N5). The study population consisted of people who fasted during the entire month of Ramadan. One hundred and sixty healthy men with no diagnosed disease who volunteered to participate in the study were selected from five mosques in different districts of the city. A list of eligible subjects was developed before the commencement of Ramadan. The selected individuals were matched for age and the socioeconomic status in different districts. Data were collected at three different times (1-7 days before, 1-4 days before the end and one month after Ramadan had ended). A flow chart for the study is presented in figure 1.

Demographic data, including age, educational level and socioeconomic status were collected by a researcher-developed questionnaire. Dietary intake was assessed by a semiquantitative food frequency questionnaire (FFQ). The FFQ's validity and reliability have been confirmed previously (27). This questionnaire consists of 168 foods with a standard portion size. The mentioned value for each food is based on recommended portion size. The questionnaire was only administered prior to and at the end of Ramadan. The amounts of macronutrients and energy intake were estimated at each of the time point.

Body composition was measured by bio-impedance body analyzer model Avis Plus 333. This device is a standard instrument for assessing the composition of the body based on a multi-frequency bioimpedance signal allowing estimation of the mass of body fat (BF), body fat percentage (BF\%), lean body mass (LBM), soft lean mass and total body water (TBW). To assess changes in blood biochemical indices, 5-ml venous blood samples were taken from the participants at each time point. Blood samples were obtained after 12-14 h 
fasting, at 8-9 am 2-5 days prior to Ramadan, at 6-8 pm on the 25-28th days of Ramadan, and at 8-9 am 28-30 days after Ramadan. After separation of blood cells by centrifugation at 3000 rpm for 15 min at $4^{\circ} \mathrm{C}$, serum was stored with $0.1 \% \mathrm{Na}_{2}$-EDTA in the freezer at $-40^{\circ} \mathrm{C}$.

Serum triglyceride (TG), total cholesterol (TC), low density lipoprotein (LDL) and high density lipoprotein (HDL) were determined quantitatively by enzymatic colorimetric kits (Pars Co., Iran) with an auto analyzer device (Technic on RA-XT, Ireland). FBS was measured according to a standard photometric method by an auto analyzer (RA1000-RAXT, Pars Co., Iran). Homeostatic model assessment-insulin resistance (HOMA-IR) and beta cell function $(\beta)$ indices were calculated by the formula below: (FPI: Fasting plasma insulin)(FPG:

Fasting plasma glucose)

HOMA-IR $=[$ FPI $(\mathrm{mIU} / \mathrm{L}) \times$ FPG $(\mathrm{mmol} / \mathrm{L})] / 22.5$

HOMA- $\% \beta=[20 \times$ FPI $(\mathrm{mU} / \mathrm{L})) /(\mathrm{FPG}(\mathrm{mmol} / \mathrm{L})-3.5]$

For the conversion of fasting glucose units from $\mathrm{mg} / \mathrm{dl}$ to $\mathrm{mmol} / \mathrm{l}$, the number was multiplied by $18(28)$.

\section{Statistics}

The data were analyzed by SPSS 16 . We analysed the data across all three time points using repeated measures analyses of variance, followed up where appropriate by paired t-tests to locate differences of interest. We used correlation to explore the relationship between weight loss during Ramadan and weight regain afterwards. Correlation was used to investigate the association between food groups and anthropometric and biochemical parameters. $\mathrm{P}<0.05$ was considered the level of significance.

\section{RESULTS}

The mean age of the participants was 39.35 \pm 10.7 (range: 21-63) years. At baseline, 160 participants were enrolled in the study, of whom eight people were excluded because of incomplete information and the data of 152 people (compliance rate 95\%) was analyzed. The 
mean weight of the participants was $76.33 \pm 11.5 \mathrm{~kg}$ before Ramadan and $74.4 \pm 11.3 \mathrm{~kg}$ at the end of Ramadan (paired t-test: $\mathrm{t}=19.95, P<0.001$ ), and had returned to the baseline level (76.31 $\mathrm{kg}$ ) one month after Ramadan (paired t-test compared to pre-Ramadan levels, $\mathrm{t}=.13, \mathrm{P}=.89$ ). BMI also decreased significantly between baseline and the end of Ramadan (paired t-test, $\mathrm{t}=$ 20.38, $P<0.001$ ) but returned to the baseline level one month later (table 1 ). There was a significant positive correlation between weight loss during Ramadan and weight regain over the month after Ramadan ( $\mathrm{R}=0.359, \mathrm{P}: 0.01)$. The mean of TBW and SLM were significantly decreased at end of Ramadan $(\mathrm{P}<0.001)$. The mean $\mathrm{BF}$ was $18.2 \pm 6.2 \mathrm{~kg}$ before Ramadan, decreased by about $0.7 \mathrm{~kg}$ and reached $17.6 \pm 6.1 \mathrm{~kg}$ at the end of Ramadan (paired t-test, $\mathrm{t}=$ 7.21, $P<0.001$ ) and had increased to $19.25 \pm 6.38 \mathrm{~kg}$ one month later (paired t-test compared to pre-Ramadan, $\mathrm{t}=-8.47, P<0.001)$. The mean weight loss and glucose levels in people who were overweight or obese were slightly higher than those who had normal weight. However, these differences were not significant. BF\% decreased by about $0.3 \%$ at the end of Ramadan compared with before Ramadan (paired t-test, $\mathrm{t}=2.91, P<0.001$ ). TBW was $41.9 \pm 5.14 \%$ before Ramadan, decreased to $41.0 \pm 4.58 \%$ at the end of Ramadan and increased to $41.1 \pm 4.93 \%$ one month later (paired t-test, $\mathrm{t}=9.24, P<0.001$ ). LBM decreased from $58.2 \pm 7.14 \mathrm{~kg}$ to $56.9 \pm 6.47$ $\mathrm{kg}$ at the end of Ramadan and increased to $57.1 \pm 6.85 \mathrm{~kg}$ one month later $(P<0.001)$. LDL cholesterol (95.4 $\pm 20.4_{\text {vs }} 98.7 \pm 20.8$, paired t-test, $\left.t=-3.32, \mathrm{p}<0.001\right)$ and $\mathrm{TC}$ (185.94 \pm 52.6 vs $192.7 \pm 39.7$, paired t-test, $\mathrm{t}=-2.21, \mathrm{p}<0.03$ ) increased during Ramadan, and then decreased, but had not returned to their baseline levels one month after Ramadan (95.4 \pm 20.4 w $96.9 \pm 22.8$,-paired t-test, NS). HDL cholesterol was not significantly different across the three different time points (ANOVA). TG decreased significantly during Ramadan $\left(151.3 \pm 83.6_{\text {vs }} 140.9 \pm 74.2\right.$, paired t-test, $\left.\mathrm{t}=2.01, \mathrm{p}<0.04\right)$ but increased dramatically and even

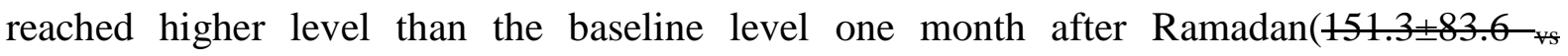

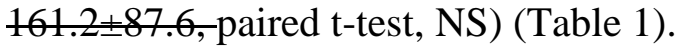


FBS decreased at the end of Ramadan (paired t-test, $t=6.7 \mathrm{p}<0.001$ ) but increased dramatically and also reached higher level than the baseline level one month later ( paired ttest, $\mathrm{t}=-4.1, \mathrm{p}<0.001$ ) The insulin level increased during Ramadan (paired t-test, $\mathrm{t}=-8.16$, $P=0.001$ ) and decreased (paired t-test, $\mathrm{t}=2.34, P=0.02$ ) but did not return to baseline level one month after Ramadan. The HOMA-IR index increased at the end of Ramadan compared with before Ramadan (paired t-test, $\mathrm{t}=-6.44 \mathrm{P}=0.001$ ). Although it subsequently decreased slightly but it had not returned to the baseline level one month later (paired t-test, $t=-6.47, \mathrm{p}=0.001$ ). HOMA- $\beta$ significantly increased at the end of Ramadan compared with before Ramadan, and decreased one month later but did not return to the baseline level (Table 1).

The consumption of all food groups (except fruits) decreased significantly during Ramadan compared with the pre- Ramadan level (Table 2). Among the macronutrients, carbohydrate intake increased significantly during Ramadan compared with before Ramadan (paired t-test, $\mathrm{t}=-4.46, \mathrm{P}<0.001$ ) both protein (paired t-test, $\mathrm{t}=17.01, \mathrm{P}<0.001$ ) and fat (paired t-test, $\mathrm{t}=13.82, \mathrm{P}<0.001$ ) intake decreased significantly during Ramadan compared with baseline. Estimated energy intake decreased significantly during Ramadan compared with before Ramadan (paired t-test, $\mathrm{t}=5.78, \mathrm{P}<0.001$ ) (Table 3). There was no significant correlation between the change in body weight and the change in food intake from before to during Ramadan $(\mathrm{p}<.05)$. There were significant associations between HDL and bread and cereals intake $(R=-0.185$, P: 0.01$)$ as well as between body weight and fruit intake $(R=0.214$, P: 0.006) before Ramadan, and between insulin and dairy products intakes $(R=0.156, P$ : 0.045), $\mathrm{LDL}$ and vegetables $(\mathrm{R}=0.194, \mathrm{P}=0.012)$ and $\mathrm{TC}$ and vegetables $(\mathrm{R}=0.213, \mathrm{P}: 0.006)$ at the end of Ramadan.

\section{DISCUSSION}


food intake levels are actually decreased during the period of Ramadan $(8,11,12,18,20)$.

Nevertheless many studies have suggested that body weight and fat mass decline during

Ramadan (6-13) suggesting individuals are in a state of negative energy balance. Consistent

with these previous studies we also observed that individuals during Ramadan lost body

weight, BMI and body fat. However, using a validated food intake measurement tool we were

also able to detect a decrease in caloric intake during the Ramadan period, supporting the idea that individuals are in negative energy balance and lose weight because of lowered intake. However, weight loss was not correlated to the change in intake. This could be because the instrument we used to monitor food intake was not accurate enough to reflect changes at the individual level. Contrasting our lack of a significant association, Shariatpanahi et al observed that participants who had greater weight loss ingested fewer calories (29). may be the primary cause of metabolic improvements. People during Ramadan usually eat in two main meals: suhoor, which is served before dawn, and iftar, which is served after sunset. In suhoor, fasting people usually have a tendency to consume little food, and this can lead to an increase in lipolysis and gluconeonogenesis so it can potential be the cause of some of the observed adverse metabolic effects. In this study, the mean of TBW and SLM were significantly decreased at the end of Ramadan. after Ramadan, fat mass had increased again to a level higher than the pre-Ramadan baseline. Besides that, muscle mass increased but did not reach its baseline level. Since the participants in this study abstained from eating and drinking on average for 17 hours each day, in the final hours of fasting, the body activates the gluconeogenesis and lipolysis processes to meet energy and glucose needs. If exacerbation of lipolysis is associated with reduction in access 
to carbohydrate, it leads to a marked increase in supply of acetyl coenzyme A. In this situation, acetyl coenzyme A is not able to enter the Krebs cycle so that it is converted into other metabolites such as ketones and cholesterol.

A previous study showed that during Ramadan, the levels of TC and TG decreased significantly. The amount of HDL cholesterol increased and remained stable and LDL decreased one month after Ramadan (30). While another study showed that TG and HDL significantly decreased, but LDL levels increased and TC did not change $(24,30)$. A study in Bojnourd, east Iran showed that the levels of cholesterol, TG, LDL cholesterol, and HDL cholesterol had all decreased by the 28th day of Ramadan compared with the first day (31). In contrast in another study, blood cholesterol and TG increased significantly during Ramadan compared with before Ramadan; however, both parameters decreased after this month (32). Different blood lipid profiles among people in Ramadan might be attributed to the different diets of Muslims during this month.

This study showed that FBS levels changed significantly over time. Two previous studies demonstrated that FBS decreased among healthy people during Ramadan fasting (3334). In contrast, a different study reported an increase in fasting glucose (35) and a third study showed variations in glucose levels(36). The increased levels of HOMA-IR, seen in the present study, represent increase in insulin resistance during Ramadan, which can be due to metabolic outcomes of fasting rather than pathological conditions. Ramadan fasting can be considered semi-starvation. In early starvation, the adaptive response of energy homeostasis involves several endocrine changes. Insulin secretion is reduced and glucagon and epinephrine release elevated in response to reduction in the concentrations of plasma glucose and free amino acid. These changes lead to decrease in muscle protein synthesis, lipogenesis and growth and increases in lipolysis and glycogenolysis. Peripheral insulin resistance increases probably due to the increase in plasma free fatty acids (37). A previous study in Turkey that examined the 
effects of fasting on biochemical and hematological parameters in healthy and overweight people, observed significant reductions in HOMA-IR and FBS in overweight individuals during fasting. Moreover, in the healthy group, HOMA-IR increased significantly but no significant change was observed in FBS (25). In contrast, study in Tehran, demonstrated that the mean FBS in fasting men aged 34-61 years decreased significantly after Ramadan while HOMA-IR did not change significantly (38). The current evidence therefore shows considerable inconsistency in the findings on HOMA-IR variation during Ramadan. This inconsistency may be due to differences in sample size, season of fasting, number of fasting days, and nutritional knowledge of different populations. Taken together, most studies have shown that fasting in Ramadan leads to decrease in blood glucose and increase in insulin sensitivity (39). The beta cell function (HOMA- $\beta$ ) significantly increased during Ramadan compared to before Ramadan. This index also exhibited a significant decrease in the third phase of the study but did not return to its level before Ramadan. A previous study in the USA showed that increased levels of FBS, insulin and HOMA-IR were significantly associated with increased risk of diabetes while increased HOMA- $\beta$ significantly reduced the risk of type 2 diabetes (40). Insulin sensitivity and insulin secretion follow a circadian pattern. In this study insulin levels had been measured at different time points for blood sampling so this may be a reason for the difference seen in the resultsfor both insulin and HOMA-IR.

A strength of the current study was the large sample of individuals that participated, relative to similar studies conducted previously. However, there were also several weaknesses and limitations. The study only included males and hence the impacts of Ramadan fasting on females could not be evaluated. Moreover, in common with most studies of Ramadan conducted in strict Muslim countries, we did not have a control group who did not partake in the fasting. Abstaining from the fasting is permitted under certain conditions for example for pregnant or lactating women, senile individuals or for individuals that are ill. 
278 None of these groups however provide suitable controls. Formally therefore, without such

279

280

281

282

283

284

285

286

287

288

289

290

291

292

293

294

295

296

297

298

299

300

301

302

303

304

305

306

controls we cannot separate the trends in time from changes due to season. Nevertheless

despite this caveat it seems likely that the patterns were caused by Ramadan and were not seasonal effects independent of the fasting behaviour.

The reduction in weight, BMI and body fat and some biochemical parameters such as

TG and FBS represents the positive health benefits of fasting during Ramadan. However

LDL cholesterol and fasting insulin increased as did HOMA-IR. These positive and negative effects were all transient as they had generally returned to baseline levels one month after Ramadan had finished.

\section{Acknowledgements}

The current study was sponsored by the Vice Chancellery of Research \& Technology Affairs at Kermanshah University of Medical Sciences, Kermanshah - Iran (Grant no. 91058). The authors are deeply grateful to all participants for their time and blood sample donation. The authors declare no conflicts of interest. Author contributions. Project design: SMN, JRS. Data collection: SMN, YP, SP, MD, PN, RM. Data analysis: SMN, RM, JRS. Writing paper. SMN, JRS.

\section{Reference}

1. Bakhotmah BA.The puzzle of self-reported weight gain in a month of fasting (Ramadan) among a cohort of Saudi families in Jeddah, Western Saudi Arabia. Nutrition Journal. 2011;10 (84):1-8. doi:10.1186/1475-2891-10-84.

2. Trepanowski JF, Bloomer RJ. The impact of religious fasting on human health. Nutrition Journal. 2010; 9:57 2891-9-57.doi:10.1186/1475-2891-9-57.

3. Richards EG. Mapping Time: The Calendar and its History.1998: pp 231-235. Oxford: Oxford University Press. 
4. Angel JF, Schwartz NE. Metabolic changes resulting from decreased meal frequency in adult male Muslims during the Ramadan fast. Nutrition reports international Journal.1975; 11:29-38.

5. Rashed AH. The fast of Ramadan no problems of the well: The sick should avoid fasting. Br Med J Qatar. 1994;48:11-7.

6. Nugraha B, Ghashang SK, Hamdan I, Gutenbrunner C. Effect of Ramadan fasting on fatigue, mood, sleepiness, and health-related quality of life of healthy young men in summer time in Germany: A prospective controlled study. Appetite, 2017 Apr 1;111:38-45. doi: 10.1016/j.appet.2016.12.030.

7. Sezen Y, Altiparmak IH, Erkus ME, Kocarslan A, Kaya Z, Gunebakmaz O, et al. Effects of Ramadan fasting on body composition and arterial stiffness. J Pak Med Assoc. 2016 Dec;66(12):1522-1527.

8. Yeoh EC, Zainudin SB, Loh WN, Chua CL, Fun S, Subramaniam T, et al. Fasting during Ramadan and Associated Changes in Glycaemia, Caloric Intake and Body Composition with Gender Differences in Singapore. Ann Acad Med Singapore. 2015 Jun;44(6):202-6.

9. López-Bueno M, González-Jiménez E, Navarro-Prado S, Montero-Alonso MA, SchmidtRioValle J. Influence of age and religious fasting on the body composition of Muslim women living in a westernized context. Nutr Hosp. 2014 Dec 16;31(3):1067-73. doi: 10.3305/nh.2015.31.3.8278.

10. Reiches MW, Moore SE, Prentice AM, Ellison PT. Endocrine responses, weight change, and energy sparing mechanisms during Ramadan among Gambian adolescent women. Am J Hum Biol. 2014 May-Jun;26(3):395-400. doi: 10.1002/ajhb.22531.

11. Norouzy A, Salehi M, Philippou E, Arabi H, Shiva F, Mehrnoosh S, et al. Effect of fasting in Ramadan on body composition and nutritional intake: a prospective study. J Hum Nutr Diet. 2013 Jul;26 Suppl 1:97-104. doi: 10.1111/jhn.12042. Epub 2013 May 17.

12. Maughan RJ, Bartagi Z, Dvorak J, Zerguini Y. Dietary intake and body composition of football players during the holy month of Ramadan. J Sports Sci. 2008 Dec;26 Suppl 3:S2938. doi: 10.1080/02640410802409675.

13. Hallak MH, Nomani MZ. Body weight loss and changes in blood lipid levels in normal men on hypocaloric diets during Ramadan fasting. Am J Clin Nutr. 1988 Nov;48(5):1197-210.

14. Harder-Lauridsen NM, Rosenberg A, Benatti FB, Damm JA, Thomsen C, Mortensen EL, et al. Ramadan model of intermittent fasting for $28 \mathrm{~d}$ had no major effect on body composition, glucose metabolism, or cognitive functions in healthy lean men. Nutrition. 2017 May;37:92103. doi: 10.1016/j.nut.2016.12.015.

15. Rohin MA, Rozano N, Abd Hadi N, Mat Nor MN, Abdullah S, Dandinasivara Venkateshaiah M. Anthropometry and body composition status during Ramadan among higher institution learning centre staffs with different body weight status. ScientificWorldJournal, 2013 Nov 7;2013:308041. doi: 10.1155/2013/308041.

16. Racinais S, Périard JD, Li CK, Grantham J. Activity patterns, body composition and muscle function during Ramadan in a Middle-East Muslim country. Int J Sports Med. 2012 Aug;33(8):641-6. doi: 10.1055/s-0032-1304645.

17. Hajek P, Myers K, Dhanji AR, West O, McRobbie H. Weight change during and after Ramadan fasting. J Public Health (Oxf). 2012 Aug;34(3):377-81. doi: 10.1093/pubmed/fdr087.

18. Alpay Güvenç. Effects of Ramadan Fasting on Body Composition, Aerobic Performance and Lactate, Heart Rate and Perceptual Responses in Young Soccer Players. J Hum Kinet. 2011 Sep; 29: 79-91. 
19. Ramadan J. Does fasting during Ramadan alter body composition, blood constituents and physical performance? Med Princ Pract. 2002;11 Suppl 2:41-6.

20. Al Ati J, Beji C, Danguir J. Increased fat oxidation during Ramadan fasting in healthy women: an adaptative mechanism for body-weight maintenance. Am J Clin Nutr. 1995 Aug;62(2):302-7.

21. Dhurandhar NV, Schoeller DA, Brown AW, Heymsfield SB, Thomas D, Sørensen TI, et al. Energy Balance Measurement Working Group. Response to 'Energy balance measurement: when something is not better than nothing'. Int J Obes (Lond). 2015 Jul;39(7):1175-6. doi: 10.1038/ijo.2015.81.

22. Nader Lessan, Ilham Saadane, Budour Alkaaf, Catherine Hambly, Nick Finer, John R. Speakman, et al. The Effects of Ramadan Fasting on Activity and Energy Expenditure (2017: Submitted).

23. Lamri-Senhadji M Y, El Kebir B, Belleville J, Bouchenak M. Assessment of dietary consumption and time-course of changes in serum lipids and lipoproteins before, during and after Ramadan in young Algerian adults. Singapore Medical Journal. 2009; 50 (3) : 288. PMID:19352573.

24. Hallak A, Nomani MZA. Body weight loss and changes in blood lipid levels in normal men on hypocaloric diets during ramadan fasting. Am J Clin Nutr 1988;48:1197-210. PMID:3189206

25. Unalacak M, Kara IH, Baltaci D, Erdem O, Bucaktepe PG. Effects of Ramadan fasting on biochemical and hematological parameters and cytokines in healthy and obese individuals. Metabolic Syndrome and Related Disorders. 2011 ;9(2):157-61.doi: 10.1089/met.2010.0084.

26. Sadiya A, Ahmed S, Siddieg HH, Babas IJ, Carlsson M. Effect of Ramadan fasting on metabolic markers, body composition, and dietary intake in Emiratis of Ajman (UAE) with metabolic syndrome. Diabetes Metab Syndr Obes 2011;4:409-16. doi:10.2147/DMSO.S24221

27. Mirmiran P, HosseiniEsfahani F, Azizi F. Relative validity and reliability of the food frequency questionnaire used to assess nutrient intake: Tehran Lipid and Glucose Study. Iranian Journal of Diabetes and Lipid Disorders. 2009;9(2):185-97.

28. Wallace TM ,Levy JC, Matthews DR. Use and abuse of HOMA modeling. Diabetes Care. 2004;27:1484-7. PMID:15161807.

29. Shariatpanahi ZV, Shariatpanahi MV, Shahbazi S, Hossaini A, Abadi A. Effect of Ramadan fasting on some indices of insulin resistance and components of the metabolic syndrome in healthy male adults. British Journal of Nutrition. 2008;100(1):147-51. PMID:18053308

30. Adlouni A, Ghalim N, Benslimane A, Lecerf JM, Saile R. Fasting during Ramadan induces a marked increase in high-density lipoprotein cholesterol and decrease in low-density lipoprotein cholesterol. Ann Nutr Metab 1997;41(4):242-9.

31. Babaee A.K, Ghasemi M, Tavakili H, Yoosefi A. Study of some biochemical parameters in male university students affected by Ramadan fasting. J university Khorasan shomali medical sci 2008;1(1):21-6

32. Navaei L, Mehrabi Y, Azizi F. Changes in body weight, blood pressure, consumption pattern and biochemical parameters in dia-betic patients during fasting in Ramadan. Iranian Journal of Endocrinology and Metabolism 2001;3(2):125-32

33. Larijani B, Zahedi F, Sanjari M, Amiri MR, Jalili RB, Adibi H, et al. The effect of ramadan fasting on fasting serum glucose in healthy adulths. Med J Malaysia 2003;58(678):680.

34. Ziaee V, Razaei M, Ahmadinejad Z, Shaikh H, Yousefi R, Yarmohammadi L, et al. The changes of metabolic profile and weight during Ramadan fasting. Singapore Med J 2006 May;47(5):409-14. 
35. Scott TG. The effect of muslim fast of ramadan on routin laborator investigation. King Abdulaziz Med J 1981;1:23.

36. Khogheer Y, Sulaiman MI, Al-Fayez SF. Ramadan fasting state of controls. Ann Saudi Med 1987;50.

37. Catharine Ross A. Modern Nutrition in health and disease. Wolters Kluwer Health/Lippincott Williams \& Wilkins. 2014 , Eleventh edition.

38. Zareh M MGhR. Study of some biochemical parameters in male university students affected by Ramadan fasting. J Sabzevar university of medical sci 2002;9(3):30-5.

39. Trepanowski JF, Bloomer RJ. The impact of religious fasting on human health. Nutrition Journal. 2010;9:57. PMID:21092212

40. Song Y, Manson JE, Tinker L, Howard BV, Kuller LH, Nathan L, et al. Insulin sensitivity and insulin secretion determined by homeostasis model assessment and risk of diabetes in a multiethnic cohort of women: the Women's Health Initiative Observational Study. Diabetes Care. 2007;30(7):1747-52. PMID:17468352 
Table 1: Anthropometric and biochemical indices before, at the end and after Ramadan*

\begin{tabular}{|c|c|c|c|c|c|c|c|}
\hline $\begin{array}{l}\text { Anthropometric } \\
\text { \&biochemical } \\
\text { Indices }\end{array}$ & $\begin{array}{c}\text { Pre- } \\
\text { Ramadan } \\
(\text { Mean } \pm \text { SD) }\end{array}$ & $\begin{array}{c}\text { Ramadan } \\
\text { (Mean } \pm \text { SD) }\end{array}$ & $\begin{array}{c}\text { Post- } \\
\text { Ramadan } \\
(\text { Mean } \pm \text { SD) }\end{array}$ & $\mathbf{P}_{1}$ & $\mathbf{P}_{2}$ & $\mathbf{P}_{3}$ & $\mathbf{P}_{4}$ \\
\hline Weight(kg) & $76.33 \pm 11.4$ & $74.22 \pm 11.2$ & $76.31 \pm 11.5$ & $<0.001$ & $<0.001$ & 0.890 & $<0.001$ \\
\hline $\operatorname{BMI}\left(\mathrm{kg} / \mathrm{m}^{2}\right)$ & $26.10 \pm 3.79$ & $25.37 \pm 3.74$ & $26.08 \pm 3.81$ & $<0.001$ & $<0.001$ & 0.699 & $<0.001$ \\
\hline WHR & $0.9 \pm 0.081$ & $0.89 \pm 0.082$ & $0.9 \pm 0.078$ & $<0.001$ & $<0.001$ & $<0.001$ & $<0.001$ \\
\hline MBF(kg) & $18.34 \pm 6.1$ & $17.60 \pm 6.2$ & $19.36 \pm 6.2$ & $<0.001$ & $<0.001$ & $<0.001$ & $<0.001$ \\
\hline TBW (\%) & $41.88 \pm 5.1$ & $40.90 \pm 4.8$ & $41.14 \pm 4.8$ & $<0.001$ & $<0.001$ & $<0.001$ & 0.002 \\
\hline PBF (\%) & $23.50 \pm 5.6$ & $23.13 \pm 5.8$ & $24.8 \pm 5.4$ & $<0.001$ & 0.003 & $<0.001$ & $<0.001$ \\
\hline LBM (kg) & $58.18 \pm 7.09$ & $56.81 \pm 6.7$ & $57.14 \pm 6.8$ & $<0.001$ & $<0.001$ & $<0.001$ & 0.001 \\
\hline SLM (kg) & $53.77 \pm 6.5$ & $52.52 \pm 6.1$ & $52.74 \pm 6.2$ & $<0.001$ & $<0.001$ & $<0.001$ & 0.028 \\
\hline LDL(mg/dl) & $95.8 \pm 20.6$ & $99.40 \pm 21.3$ & $96.95 \pm 22.8$ & 0.009 & 0.001 & 0.352 & 0.052 \\
\hline HDL(mg/dl) & $44.70 \pm 7.9$ & $45.59 \pm 9$ & $46.25 \pm 9.3$ & 0.033 & 0.168 & 0.010 & 0.195 \\
\hline TG(mg/dl) & $151.44 \pm 85.2$ & $140.44 \pm 75.2$ & $161.25 \pm 87.6$ & 0.001 & 0.044 & 0.103 & $<0.001$ \\
\hline $\mathrm{TC}(\mathrm{mg} / \mathrm{dl})$ & $187.76 \pm 52.4$ & $193.62 \pm 40.3$ & $190.72 \pm 41.3$ & 0.155 & 0.071 & 0.373 & 0.217 \\
\hline FBS(mg/dl) & $80.17 \pm 19.3$ & $72.06 \pm 18.4$ & $81.3 \pm 21.5$ & $<0.001$ & $<0.001$ & 0.630 & $<0.001$ \\
\hline Insulin(mg/dl) & $4.63 \pm 5.33$ & $11.32 \pm 9$ & $9.02 \pm 7.54$ & $<0.001$ & $<0.001$ & $<0.001$ & 0.020 \\
\hline HOMA-IR & $0.93 \pm 1.09$ & $2.01 \pm 1.66$ & $1.84 \pm 1.62$ & $<0.001$ & $<0.001$ & $<0.001$ & 0.372 \\
\hline HOMA- $\beta$ & $17.62 \pm 24.1$ & $55.57 \pm 49.3$ & $37.79 \pm 36.2$ & $<0.001$ & $<0.001$ & $<0.001$ & 0.001 \\
\hline \multicolumn{8}{|c|}{$\begin{array}{l}\text { Body mass index (BMI), waist-to-hip ratio (WHR), mass of body fat (MBF), Total body water (TBW), percent } \\
\text { of body fat (PBF), lean body mass (LBM), soft lean Mass (SLM), Low density lipoprotein (LDL), High density } \\
\text { lipoprotein (HDL), Triglyceride (TG), Total cholesterol (TC), Fasting blood glucose (FBS). }\end{array}$} \\
\hline $\begin{array}{l}{ }^{*} \text { ANOVA test was us } \\
\text { Ramadan. } \\
\mathbf{P}_{1: \text { comparison of }} \\
\mathbf{P}_{\text {2: comparison of }} \\
\mathbf{P}_{\text {3: comparison of }} \\
\mathbf{P}_{4: \text { : comparison }}\end{array}$ & $\begin{array}{l}\text { ed to investigate } \\
\text { neans before, at } \\
\text { neans before an } \\
\text { neans before, an }\end{array}$ & $\begin{array}{l}\text { anthropometric } \\
\text { the end and a mo } \\
\text { the end of Ram }\end{array}$ & $\begin{array}{l}\text { id biochemical i } \\
\text { th after Ramada } \\
\text { aman } \\
\text { amadan } \\
\text { amadan }\end{array}$ & dices befo & e, at the $\mathrm{e}$ & hd and a $\mathrm{n}$ & onth after \\
\hline
\end{tabular}


Table 2: Changes in the consumption of food groups before and the end of Ramadan

\begin{tabular}{|c|c|c|c|}
\hline $\begin{array}{l}\text { Food Groups } \\
\text { (serving/day) }\end{array}$ & $\begin{array}{l}\text { Pre-Ramadan } \\
\text { (Mean } \pm \text { SD) }\end{array}$ & $\begin{array}{l}\text { Ramadan } \\
\text { (Mean } \pm \text { SD) }\end{array}$ & $\begin{array}{r}\text { p-valteß1 } \\
432\end{array}$ \\
\hline Breads and Cereals & $6.79 \pm 2.90$ & $5.71 \pm 1.21$ & $<0.0,033$ \\
\hline Dairy Products & $3.45 \pm 1.75$ & $1.85 \pm 0.69$ & $<0.001$ \\
\hline Meats & $3.97 \pm 2.16$ & $2.24 \pm 0.85$ & $<0.034$ \\
\hline Fruits & $5.97 \pm 3.56$ & $8.50 \pm 2.67$ & $<0.0 P P$ \\
\hline Vegetables & $0.92 \pm 0.47$ & $0.90 \pm 0.63$ & $<0.0136$ \\
\hline Fat and Oils & $2.29 \pm 0.89$ & $2.33 \pm 0.87$ & $<0.0034$ \\
\hline Others & $2.24 \pm 1.64$ & $2.42 \pm 2.17$ & $<0.001$ \\
\hline
\end{tabular}

439

440

441

442

443

444

445

446

447

448

449

450

451

452

453

454

455

456

457

458

459

460

461

462

463

464 
Table 3: Changes in the consumption of Macronutrients (g/day) and Energy intake (MJ/day) before 469 and at the end of Ramadan

470

471

\begin{tabular}{|lccc|}
\hline & \multicolumn{2}{c|}{ (Mean \pm SD) } \\
Macronutrients & Pre-Ramadan & Ramadan & \multirow{2}{*}{ P-Value } \\
\cline { 2 - 3 } & & & $<0.001$ \\
\hline Carbohydrate & $271.24 \pm 93.70$ & $276.33 \pm 68.78$ & $<0.001$ \\
\hline Protein & $77.72 \pm 25.30$ & $49.50 \pm 11.68$ & $<0.001$ \\
\hline Fat & $48.66 \pm 17$ & $32.17 \pm 10.20$ & $<0.001$ \\
\hline Energy intake & $7.6 \pm 2.3$ & $6.6 \pm 1.6$ & \\
\hline
\end{tabular}

473

474

475

476

477

478

479

480

481

482

483

484

485

486

487

488

489

490

491

492

493

494 


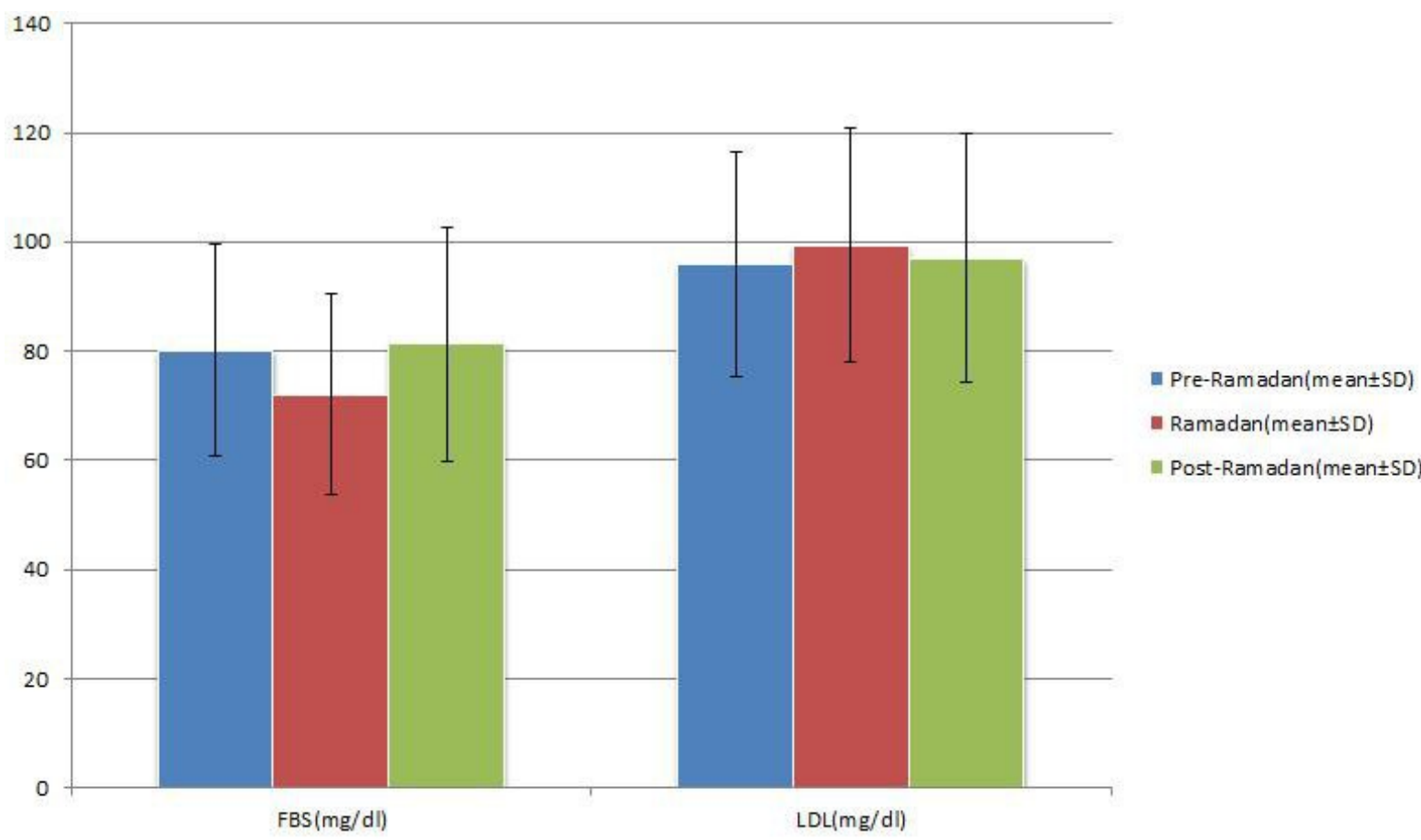

498 Figure 1. Fasting blood sugar (FBS) and low density lipoprotein (LDL) in people before, at 499 the end, and one month after Ramadan. Error bars are standard deviation. 


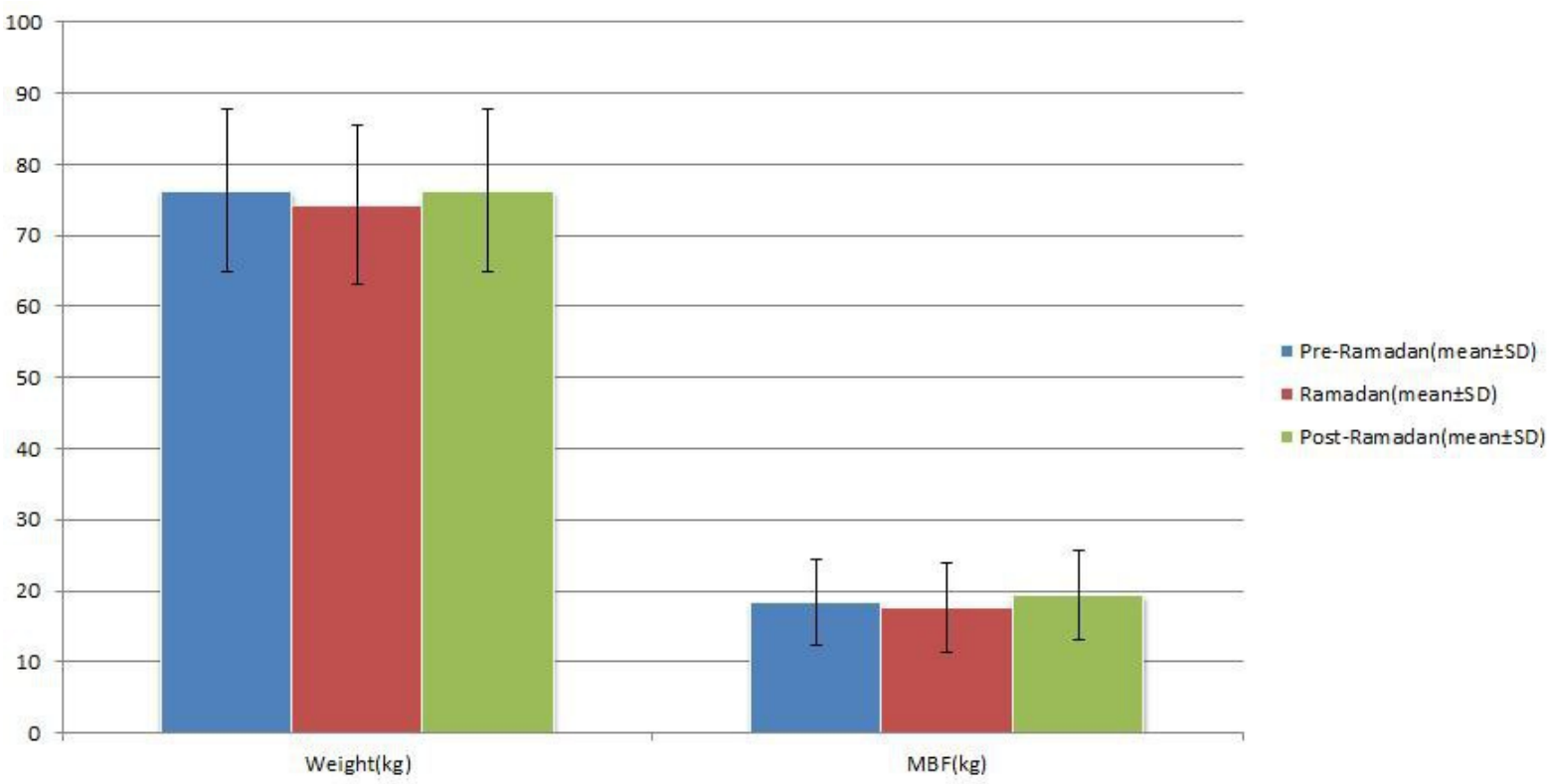

518 Figure 2. Body weight (FBS) and mass of body fat (MBF) (both in kg) in fasted people

519 before, during and one month after Ramadan. Error bars are standard deviation. 
STROBE Statement—checklist of items that should be included in reports of observational studies

\begin{tabular}{|c|c|c|}
\hline & $\begin{array}{c}\text { Item } \\
\text { No }\end{array}$ & Recommendation \\
\hline \multirow[t]{2}{*}{ Title and abstract } & \multirow[t]{2}{*}{1} & $\begin{array}{l}\text { Effects of Ramadan on food intake, glucose homeostasis, lipid profiles and } \\
\text { body composition (lines } 1 \text { and } 2 \text { ) }\end{array}$ \\
\hline & & $\begin{array}{l}\text { Food intake, glucose homeostasis, lipid profiles and body composition } \\
\text { before, during and after Ramadan fasting among } 160 \text { healthy men were } \\
\text { investigated. Ramadan fasting may lead to some beneficial effects such as a } \\
\text { decrease in FBS, weight and BFP in healthy adults. However, it also led to } \\
\text { increased insulin resistance. (lines 53-74) }\end{array}$ \\
\hline \multicolumn{3}{|l|}{ Introduction } \\
\hline Background/rationale & 2 & $\begin{array}{l}\text { At least, one billion of the total global population of Muslims abstain from } \\
\text { eating or drinking from sunrise to sunset during the holy month of } \\
\text { Ramadan. Adherence to the Ramadan fast causes radical changes in eating } \\
\text { patterns, and the quality of ingested nutrients. The effects of Ramadan on } \\
\text { anthropometric and metabolic indices are inconsistent across studies so the } \\
\text { aim of the present study was investigating effect of Ramadan on } \\
\text { anthropometric and metabolic indices (lines 79-99) }\end{array}$ \\
\hline Objectives & 3 & $\begin{array}{l}\text { In the present study we investigated changes in anthropometric indices, } \\
\text { fasting blood sugar, serum lipid profiles, serum insulin and insulin } \\
\text { resistance at three times (before, at the end of and one month after } \\
\text { Ramadan) and food intake before and during Ramadan (lines 99-102. }\end{array}$ \\
\hline \multicolumn{3}{|l|}{ Methods } \\
\hline Study design & 4 & This study was an observational study (line 104) \\
\hline Setting & 5 & $\begin{array}{l}\text { Participants in the study were selected from five mosques in different } \\
\text { districts of Kermanshah a province in west of Iran. Data were collected at } \\
\text { three different times (1-7 days before, 1-4 days before the end and one } \\
\text { month after Ramadan. (lines 107-113) }\end{array}$ \\
\hline Participants & 6 & $\begin{array}{l}\text { The study population consisted of people who fasted during the entire } \\
\text { month of Ramadan. One hundred and sixty healthy men with no diagnosed } \\
\text { disease who volunteered to participate in the study were selected from five } \\
\text { mosques in different districts of the city. A list of eligible subjects was } \\
\text { developed before the commencement of Ramadan. (lines 107-112) }\end{array}$ \\
\hline
\end{tabular}

Variables
7 Demographic data, including age, educational level and socioeconomic status were collected by a researcher-developed questionnaire. Dietary intake was assessed by a semi-quantitative food frequency questionnaire (FFQ). Body composition was measured by bio-impedance body analyser. 5-ml venous blood samples were taken from the participants at each time point. After separation of blood cells by centrifugation at $3000 \mathrm{rpm}$ for 15 
min at $4^{\circ} \mathrm{C}$, serum was stored with $0.1 \% \mathrm{Na}_{2}$-EDTA in the freezer at $-40^{\circ} \mathrm{C}$. Serum triglyceride (TG), total cholesterol (TC), low density lipoprotein (LDL) and high density lipoprotein (HDL) were determined quantitatively by enzymatic colorimetric kits (Pars Co., Iran) with an auto analyzer device (Technic on RA-XT, Ireland). FBS was measured according to a standard photometric method by an auto analyzer (RA1000-RAXT, Pars Co., Iran). Homeostatic model assessment-insulin resistance (HOMA-IR) and beta cell function $(\beta)$ indices were calculated (lines 115-141)

Data sources/ measurement
The FFQ's validity and reliability have been confirmed. This questionnaire consists of 168 foods with a standard portion size. The mentioned value for each food is based on recommended portion size. The questionnaire was only administered prior to and at the end of Ramadan. The amounts of macronutrients and energy intake were estimated at each of the time point. Weight, body mass index (BMI), waist-to-hip ratio, mass of body fat (BF), body fat percentage (BF\%), lean body mass (LBM), soft lean mass and total body water (TBW) were measured by bio-impedance body analyser. Blood samples were obtained after 12-14 h fasting, at 8-9 am 2-5 days prior to Ramadan, at 6-8 pm on the 25-28th days of Ramadan, and at 8-9 am 28-30 days after Ramadan. After separation of blood cells by centrifugation at $3000 \mathrm{rpm}$ for $15 \mathrm{~min}$ at $4^{\circ} \mathrm{C}$, serum was stored with $0.1 \%$ Na2-EDTA in the freezer at $-40^{\circ} \mathrm{C}$.

(lines 115-126)

Bias 9 It was not possible to blind people to the fact they were engaged in

Ramadan fasting. Hence there could be a bias in their reporting as they were aware of the stage in the protocol they were at.

Study size 10 The study population consisted of people who fasted during the entire month of Ramadan. One hundred and sixty healthy men with no diagnosed disease who volunteered to participate in the study were selected from five mosques in different districts of the city (lines 108-110)

Quantitative variables 11 Dietary intake was assessed by a semi-quantitative food frequency questionnaire (FFQ). Body composition was measured by bio-impedance body analyser. 5-ml venous blood samples were taken from the participants at each time point. After separation of blood cells by centrifugation at 3000 rpm for $15 \mathrm{~min}$ at $4^{\circ} \mathrm{C}$, serum was stored with $0.1 \% \mathrm{Na}_{2}$-EDTA in the freezer at $-40^{\circ} \mathrm{C}$. Serum triglyceride (TG), total cholesterol (TC), low density lipoprotein (LDL) and high density lipoprotein (HDL) were determined quantitatively by enzymatic colorimetric kits (Pars Co., Iran) with an auto analyzer device (Technic on RA-XT, Ireland). FBS was measured according to a standard photometric method by an auto analyzer (RA1000-RAXT, Pars Co., Iran). Homeostatic model assessment-insulin resistance (HOMA-IR) and beta cell function $(\beta)$ indices were calculated (lines 115-141)

Statistical methods

12 For comparison of the quantitative variables, repeated measurement test was conducted for three parameters and Post Hoc (Tukey test) was used for two of these. $\mathrm{P}<0.05$ was considered the level of significance. Correlation was 
used to investigate the association between food groups and anthropometric and biochemical parameters.

(lines 142-147)

Continued on next page 


\begin{tabular}{|c|c|c|}
\hline Results & & \\
\hline Participants & $13^{*}$ & $\begin{array}{l}\text { One hundred and sixty healthy men with no diagnosed disease who volunteered to } \\
\text { participate in the study were selected from five mosques in different districts of the } \\
\text { city. A list of eligible subjects was developed before the commencement of } \\
\text { Ramadan. The selected individuals were matched for age and the socioeconomic } \\
\text { status in different districts. Data were collected at three different times (1-7 days } \\
\text { before, 1-4 days before the end and one month after Ramadan had ended). (lines } \\
\text { 108-110) }\end{array}$ \\
\hline Descriptive & $14^{*}$ & See table 1 \\
\hline Outcome data & $15 *$ & See table 1 and 2 \\
\hline Main results & 16 & $\begin{array}{l}\text { During Ramadan individuals ate less food (in all food categories) and lost weight. } \\
\text { There was an improvement in most health indicies but insulin resistance increased. } \\
\text { These changes were transient and returned towards baseline after Ramadan was } \\
\text { over. (lines 149-194) }\end{array}$ \\
\hline
\end{tabular}

\begin{tabular}{lcl}
\hline $\begin{array}{l}\text { Other analyses } \\
\text { Discussion }\end{array}$ & 17 & There was no subgroups in this study \\
\hline $\begin{array}{lll}\text { Key results } \\
\text { Limitations }\end{array}$ & 19 & $\begin{array}{l}\text { Ramadan fasting generates some improvement in health markers but these changes } \\
\text { are transitory (lines 197-255). }\end{array}$ \\
& $\begin{array}{l}\text { The study only included males and hence the impacts of Ramadan fasting on } \\
\text { females could not be evaluated. Moreover, like many studies performed in strict } \\
\text { muslim countries it was not possible to have a control group that did not adhere to } \\
\text { Ramadan restrictions (lines 256-266) }\end{array}$ \\
\hline Interpretation & 20 & $\begin{array}{l}\text { Ramadan fasting may lead to some beneficial effects such as a decrease in FBS, } \\
\text { weight and BFP in healthy adults. However, it also led to increased insulin } \\
\text { resistance. The effects were all transitory (lines 268-272) }\end{array}$ \\
\hline Generalisability & 21 & \begin{tabular}{l} 
There is no reason to believe these results are not widely applicable. \\
\hline
\end{tabular}
\end{tabular}

\section{Other information}

\begin{tabular}{ll}
\hline Funding & $\begin{array}{l}\text { The current study was sponsored by the Vice Chancellery of Research \& } \\
\text { Technology Affairs at Kermanshah University of Medical Sciences, Kermanshah - } \\
\text { Iran (Grant no. 91058). (lines 276-277) }\end{array}$
\end{tabular}

$547 *$ Give information separately for cases and controls in case-control studies and, if applicable, for exposed and 548 unexposed groups in cohort and cross-sectional studies. 